\title{
Psoriasis anular
}

\author{
Mónica López Valcárcel ${ }^{a}$, Cristina Faura Berruga ${ }^{b}$
}

\author{
a Medicina de Familia y \\ Comunitaria. Gerencia Atención \\ Primaria de Albacete. CS Zona \\ 8. Albacete. España. \\ b Servicio de Dermatología \\ y Venereología. Complejo \\ Hospitalario Universitario de \\ Albacete. Albacete. España.

\section{Correspondencia:} \\ Mónica López Valcárcel. \\ Centro de Salud Zona 8 \\ (Albacete). \\ Correo electrónico: \\ monica_18_661@hotmail.com
}

Recibido el 22 de diciembre de 2013.

Aceptado para su publicación el 20 de enero de 2014.

\section{RESUMEN}

La psoriasis es una enfermedad cutánea inflamatoria crónica que cursa en brotes con expresiones clínicas muy variadas, siendo la presentación más habitual en pápulas o placas eritematodescamativas recidivantes. Hay formas de presentación menos frecuentes en las que será necesario hacer diagnóstico diferencial con otras entidades, ya que modificaría nuestra actitud y tratamiento.

Este es el caso de la psoriasis anular, variedad poco frecuente, en la que deberemos someter al paciente a un exhaustivo examen físico en busca de otras lesiones cutáneas que nos puedan orientar el diagnóstico y realizar un cultivo fúngico y una biopsia cutánea para confirmar nuestra sospecha diagnóstica.

Palabras clave: Psoriasis anular. Clínica. Diagnóstico.

\section{ABSTRACT}

\section{Annular psoriasis}

Psoriasis is a chronic inflammatory skin disease which occurs in outbreaks with very different clinical expressions, being the most frequent in recurrent scaly erythematous papules or plaques. There are other less frequent presentation forms which require differential diagnosis from other entities as they may require a different clinical approach and therapy.

This is the case of annular psoriasis, an uncommon variant in which the physician must carry out an exhaustive physical examination of the patient to find other skin lesions that can orientate diagnosis. A fungal culture and a cutaneous biopsy must be performed in order to confirm the suspected diagnosis.

Keywords: Annular psoriasis. Clinic. Diagnosis.

\section{INTRODUCCIÓN}

La psoriasis es una enfermedad cutánea inflamatoria asociada a una predisposición poligénica y a factores desencadenantes (infecciones bacterianas, traumatismos o fármacos). Presenta una prevalencia en países occidentales del 1,5 al $2 \%$ con la misma incidencia en hombres que en mujeres ${ }^{1}$.

Sus expresiones clínicas son variadas, siendo la presentación más habitual en pápulas o placas eritematodescamativas recidivantes. Se trata de una enfermedad crónica que cursa en brotes y que asocia una gran morbilidad además de una importante alteración de la calidad de vida de las personas que la padecen.

\section{OBSERVACIONES CLÍNICAS}

Mujer de 55 años, sin antecedentes médicos de interés, que acudió a la consulta de Dermatología derivada desde la consulta de Atención Primaria por presentar lesiones cutáneas asintomáticas en miembros inferiores, de 
un año de evolución, que no habían mejorado tras tratamiento tópico con antifúngicos y corticoides durante 2 meses. A la exploración física encontramos placas eritematosas anulares de borde bien definido e infiltrativo, con aclaramiento central en región pretibial bilateral (figuras 1 y 2).

Se solicita biopsia cutánea de las lesiones para cultivo microbiológico fúngico y análisis anatomopatológico, sin iniciar previamente ningún tratamiento para no modificar o alterar los resultados. En el cultivo para hongos no se observaron formas fúngicas; y en el informe anatomopatológico se observaba en la biopsia cutánea ortoqueratosis con algunos focos de paraqueratosis y neutrófilos. Discreta acantosis y celularidad linfoide perivascular en dermis papilar junto a algunos hematíes extravasados.

En la siguiente visita, la paciente refirió la aparición de nuevas lesiones en ambos codos, observándose placas eritematosas-descamativas (figura 3). Tras los hallazgos clínicos y los resultados de las pruebas complementarias, se llegó al diagnóstico de psoriasis vulgar tipo anular. Se pautó betametasona asociado a calcipotriol tópico cada 24 horas y helioterapia, con la mejoría clínica de la paciente.

\section{COMENTARIOS}

La psoriasis es una dermatosis inflamatoria de etiología desconocida que puede aparecer a una edad temprana o tardía, siendo los primeros los que suelen padecer formas más graves y en general, con antecedentes familiares positivos ${ }^{1,2}$. Este trastorno se asocia a una predisposición poligénica aumentando de forma importante el número de hijos afectos cuando ambos padres padecen la enfermedad, llegando al $41 \%{ }^{2}$. Los tipos de antígenos leucocitarios humanos (HLA) que intervienen en este aumento de frecuencia son varios pero el alelo HLACw6 parece ser el más relacionado con la misma. Además de los aspectos hereditarios, se habla de factores desencadenantes como traumatismo físico (fenómeno de Koebner), infecciones bacterianas, estrés, clima, fármacos y alcoholismo ${ }^{1,2}$. Es considerada una enfermedad sistémica de base inmunológica en la que intervienen predominantemente los linfocitos T CD8+, provocando una alteración de la citocinética de los queratinocitos con un acortamiento del ciclo celular y una producción mayor de células epidérmicas.

La psoriasis se puede clasificar en tres grandes grupos: psoriasis en placas, psoriasis eritrodérmica y psoriasis pustulosa. En este caso nos vamos a centrar en la psoriasis en placas, que a su vez incluye diferentes presentaciones clínicas como la psoriasis en gotas aguda, en placas, palmo plantar e invertida. De todas ellas, las dos variedades más frecuentes son la psoriasis en gotas aguda y la psoriasis en placas crónica y estable. La lesión típica de esta última consiste en una pápula eritematosa bien delimitada, que confluye con otras formando placas geográficas y policíclicas cubiertas por escamas laminares fáciles de desprender al rascado llegando a aparecer pequeñas gotas de sangrado (signo de Auspitz) ${ }^{1,2}$. Las localizaciones más comunes son codos, rodillas, región sacra, glúteos y cuero cabelludo y suelen presentarse de forma

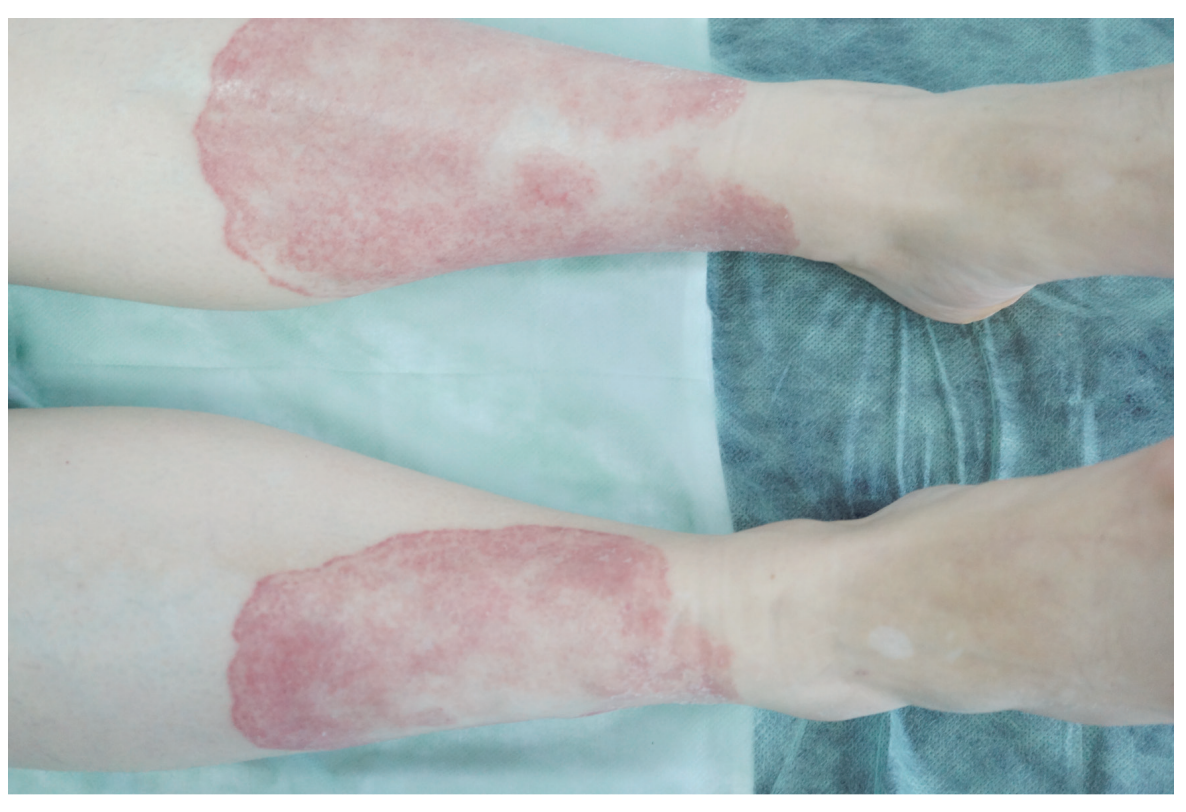

Figura 1. Placas eritematosas anulares de borde bien definido e infiltrativo en región pretibial bilateral 


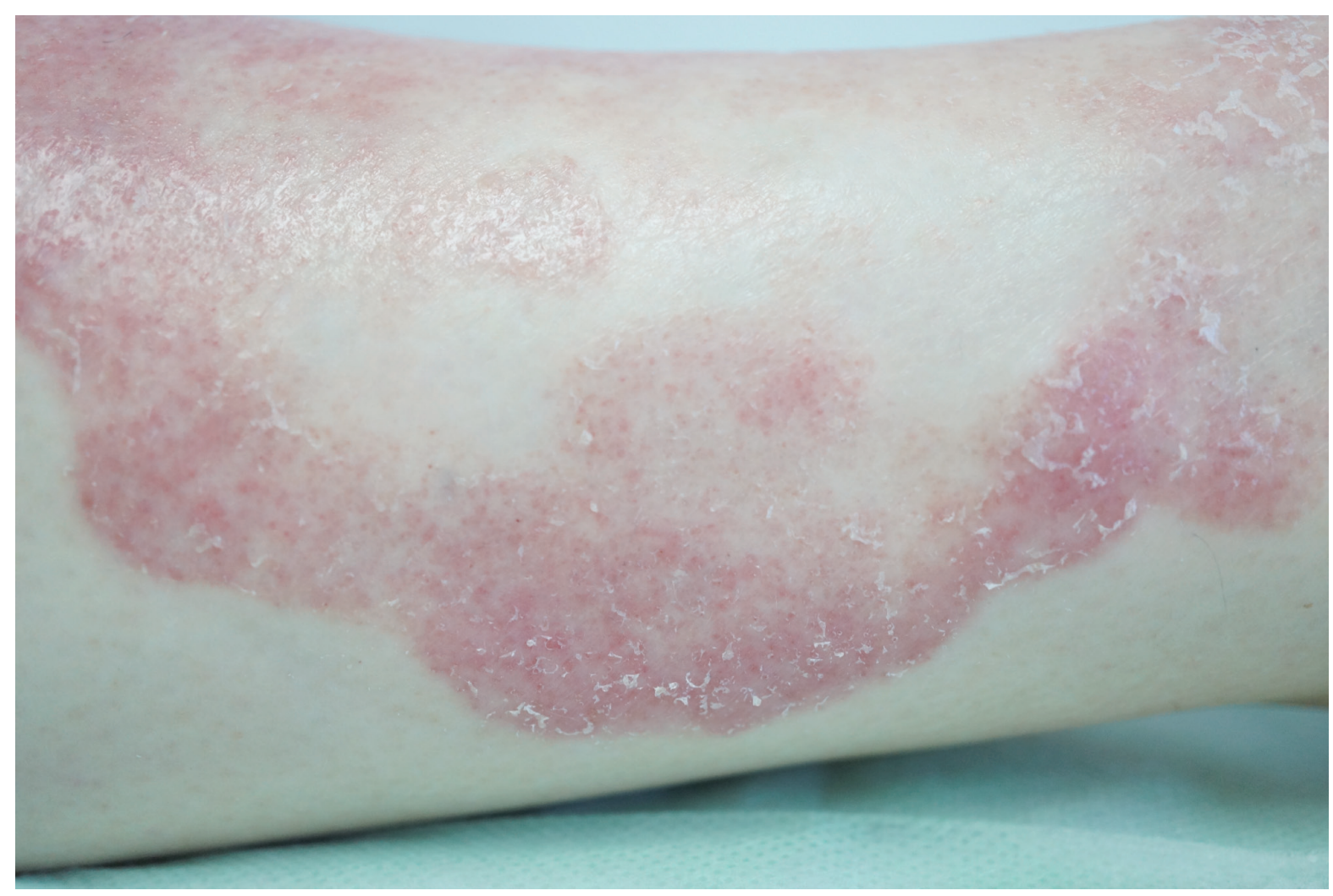

Figura 2. Detalle de una placa eritematosa con borde bien definido y aclaramiento central

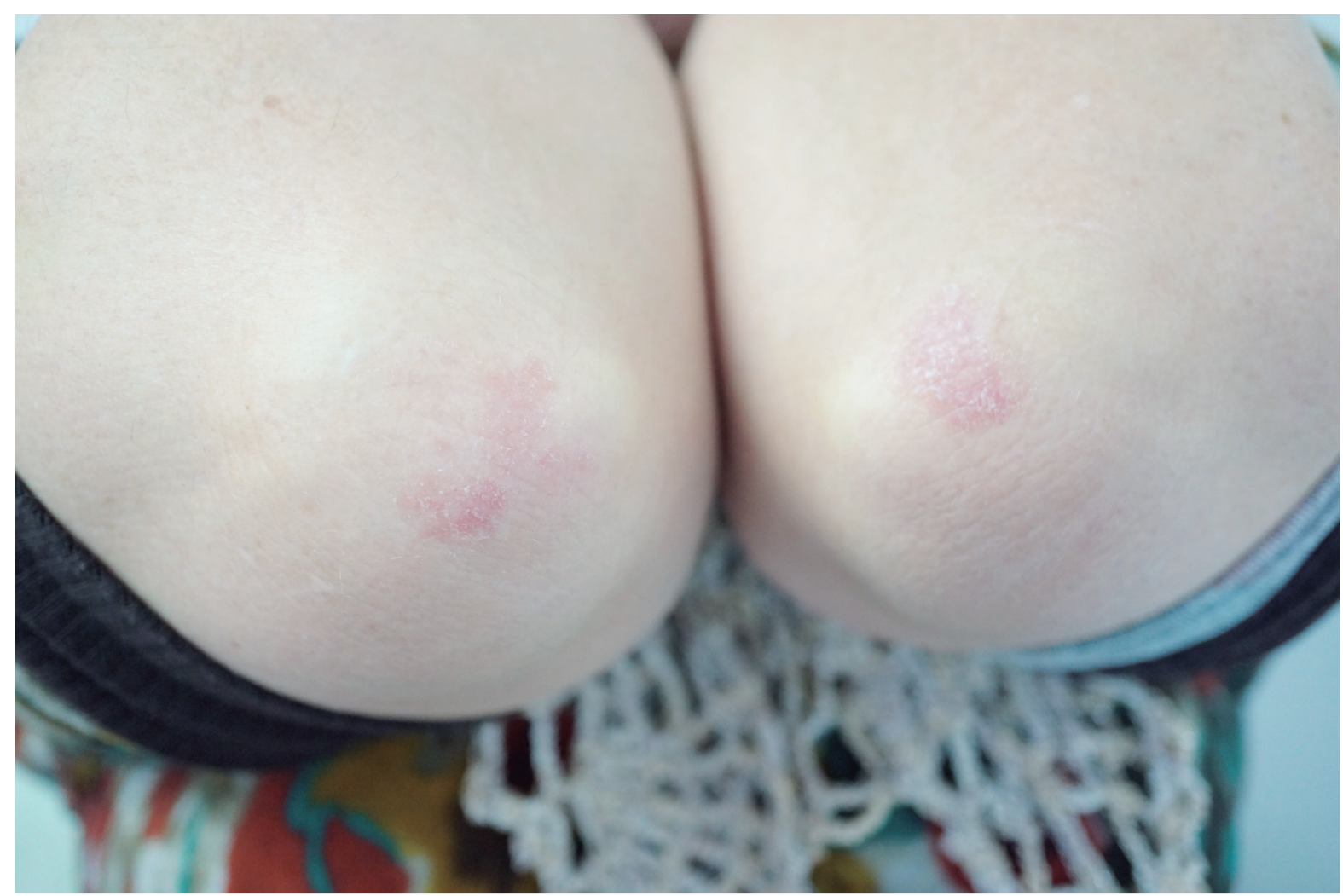

Figura 3. Placas eritematosas-descamativas en ambos codos 
bilateral. Otras regiones que debemos explorar son las palmas y plantas de los pies que podrían ser las únicas regiones afectadas, cara, regiones perianal, genital y pliegues corporales (que se afectan en la psoriasis invertida) y por último las uñas, en las que debemos buscar lesiones punteadas, hiperqueratosis subungueal, onicolisis y manchas de aceite (patognomónicas) $^{1}$.

En ocasiones, estas placas pueden presentar una remisión parcial dando como resultado lesiones anulares, serpiginosas y arciformes, como en el caso de nuestra paciente. Ante la presentación clínica de lesiones anulares habría que descartar otros posibles diagnósticos como tiña corporal, granuloma anular, eritema anular centrífugo y micosis fungoide ${ }^{3,4}$. Debido a la gran similitud clínica con estas otras entidades, a nuestra paciente se le pautó en la consulta de Atención Primaria tratamiento con antifúngicos tópicos ante la sospecha de tiña corporal.

La tiña corporal es una infección por dermatofitos localizada en tronco, piernas, brazos o cuello que es más prevalente entre personas que tienen contacto con animales ${ }^{4}$. Las lesiones cutáneas suelen ser placas con bordes nítidos, eritematodescamativos e incluso con pústulas o vesículas en los márgenes; estas placas tienen un aclaramiento central por lo que tienen morfología anular. La confirmación diagnóstica nos la dará el cultivo fúngico de una muestra de escamas o de una pústula/vesícula.

El granuloma anular es una enfermedad cutánea inflamatoria granulomatosa autolimitada y asintomática, más frecuente en niños y adultos jóvenes, en la que aparecen pápulas y placas eritematosas, suaves, brillantes, con aspecto de collar de cuentas y con disposición anular localizadas habitualmente en dorso de manos y pies, codos y rodillas que en general no requieren tratamiento ${ }^{5}$. En el $75 \%$ de los pacientes la enfermedad remite antes de los 2 años, aunque puede recurrir.

La micosis fungoide es el linfoma cutáneo de células $T$ más frecuente ${ }^{6}$. En esta entidad, el correcto diagnóstico a menudo es precedido por distintos diagnósticos erróneos como psoriasis, dermatitis numular y parapsoriasis en grandes placas. Las lesiones cutáneas se clasifican en parches, placas y estadio tumoral. En la primera fase de la enfermedad, los parches son placas eritematosas, redondeadas, ovaladas, arciformes, anulares, con o sin descamación y de configuración extraña, respetando a menudo áreas expuestas. Debe sospecharse en aquellos pacientes con una psoriasis "atípica" o refractaria al tratamiento. El diagnóstico definitivo se hace mediante confirmación histológica.

Por último, el eritema anular centrífugo es una dermatosis caracterizada por la aparición de lesiones anulares de crecimiento centrífugo que persisten en el tiempo ${ }^{7}$. Habitualmente es idiopática, aunque en ocasiones se ha relacionado con factores desencadenantes como infecciones, tumores malignos, discrasias hematológicas o drogas. Lo característico es la aparición de lesiones papulosas que se extienden de manera centrífuga transformándose en placas anulares que pueden llegar a ser de gran tamaño y se localizan de forma más frecuente en tronco y porción proximal de extremidades en la mayoría de los casos asintomáticas. La clave del diagnóstico nos la dará la anatomía patológica y la evolución de la enfermedad, que puede persistir durante años resolviéndose algunas lesiones y apareciendo otras nuevas.

Con todo ello, podemos concluir que la psoriasis anular es una forma de presentación clínica poco frecuente en la que es necesario hacer diagnóstico diferencial con otras entidades, ya que modificaría nuestra actitud y tratamiento. Por ello, ante un paciente con lesiones anulares deberemos realizar un exhaustivo examen físico en busca de otras lesiones cutáneas que nos puedan orientar el diagnóstico y realizar un cultivo fúngico y una biopsia cutánea para confirmar nuestra sospecha diagnóstica.

\section{BIBLIOGRAFÍA}

1. Wolff K, Allen Johnson R. Psoriasis. En: Berra C, Carini F, Esquerdo MA, Graiver J, Klajn D, López M, Olives C, Taveira J, Yebra P, editores. Fitzpatrick: Atlas en Color y Sinopsis de Dermatología Clínica. 6a ed. Buenos Aires: Médica Panamericana; 2010. p. 53-61.

2. Ferrándiz C. Dermatosis eritematoescamosas (I). Psoriasis. Eritrodermias. En: Ferrándiz C, editor. Dermatología clínica. $3^{\mathrm{a}}$ ed. Barcelona: Elsevier España; 2009. p. 175-186.

3. Alarcon H, Cortez B, Navarrete G. Psoriasis anular. Comunicación de un caso. Rev Cent Dermatol Pascua. 2000;9(1):11-14

4. Hsu S, Le EH, Khoshevis MR. Differential diagnosis of annular lesions. Am Fam Physician. 2001;64(2):289-96.

5. Jang EJ, Lee JY, Kim MK, Yoon TY. Erythematous granuloma annulare. Ann Dermatol. 2011;23(3):409-11.

6. Yamashita T, Abbade LP, Marques ME, Marques SA. Mycosis fungoides and Sézary syndrome: clinical, histopathological and immunohistochemical review and update. An Bras Dermatol. 2012;87(6):817-28; quiz 829-30.

7. Mir A, Terushkin V, Fischer M, Meehan S. Erythema annulare centrifugum. Dermatol Online J. 2012;18(12):21. 